\title{
Acupuncture is associated with a positive effect on odour discrimination in patients with postinfectious smell loss-a controlled prospective study
}

\author{
Tanja Drews $^{1,2} \oplus \cdot$ Thomas Hummel $^{1} \cdot$ Bettina Rochlitzer $^{1,3} \cdot$ Bettina Hauswald $^{1} \cdot$ Antje Hähner $^{1}$
}

Received: 5 February 2021 / Accepted: 4 May 2021 / Published online: 25 May 2021

(c) The Author(s) 2021

\begin{abstract}
Introduction Smell disorders are common in the general population and occur e.g., after infections, trauma or idiopathically Treatment strategies for smell loss range from surgery, medication to olfactory training, depending on the pathology, but they are limited This study examined the effect of acupuncture on olfactory function.

Methods Sixty patients with smell loss following infections of the upper respiratory tract were included in this investigation Half of the study group were randomly assigned to verum acupuncture and the other half to sham acupuncture Olfaction was measured by means of the "Sniffin' Sticks" test battery (odour threshold, discrimination and identification).

Results Compared to sham acupuncture, verum was associated with an improvement of smell function as measured by the TDI score $(p=0.039)$ The improvement was largely determined by improvement in odour discrimination, and was significantly better in patients with a shorter duration of the disorder.

Conclusion The present results suggest that acupuncture is an effective supplementary treatment option for patients with olfactory loss.
\end{abstract}

Keywords Acupuncture $\cdot$ Smell loss · Olfaction · Sniffin' sticks

\section{Introduction}

Olfactory impairment is common in the general population and results in a loss of quality of life [1,2]. While there are several valid and reliable tools available for the diagnosis of olfactory loss, the treatment possibilities of olfactory dysfunction are limited Causes of smell disorders include sinunasal diseases, acute infections of the upper respiratory tract, head trauma, neurodegenerative diseases, medication including chemotherapy, environmental factors and ageing

Tanja Drews

Tanja.Drews@uniklinikum-dresden.de

1 Department of Otorhinolaryngology, Smell and Taste Clinic, Technische Universität Dresden, Technical University of Dresden Medical School, Fetscherstrasse 74, 01307 Dresden, Germany

2 Department of Otorhinolaryngology, Bundeswehrkrankenhaus Berlin, Scharnhorststr 13, 10115 Berlin, Germany

3 Klinik Für Augenheilkunde, Städtisches Klinikum Görlitz, Girbigsdorfer Str 1-3, Görlitz, Germany
[3-5]. In effect, approximately 5\% of the population are estimated to exhibit functional anosmia with the prevalence being highest in the older population [6,7].

Treatment strategies for smell loss are related to the cause of the disorder Particularly effective therapies are available for chronic inflammation of the upper airway system including surgery or topical or systemic anti-inflammatory medication $[8,9]$. Interestingly, in clinical routine topical steroids are used irrespective of the aetiology [10]. Another effective method in treating various forms of smell loss is olfactory training [11]. Systematic, repeated exposure to odours may lead to an improvement of olfactory function in patients with post-infectious, posttraumatic and neurodegenerative smell loss [11-15]. Nevertheless, apart from these treatment options, therapies for olfactory loss are relatively poorly developed [16, 17].

Hence, the present study focuses on the treatment of patients with postinfectious smell loss who represent one of the largest groups of patients with olfactory disorders with about $18-45 \%$ of patients presenting themselves with smell loss [1]. Postinfectious smell loss is caused by an infection of the upper respiratory tract (URTI) that persists after the 
infection has passed [18]. The exact pathological mechanism is unclear but its possible lesion sites include damage to the sustentacular cells or the olfactory receptor neurons in the mucosa or the olfactory bulb [19, 20]. URTI-associated smell loss typically occurs after the fifth decade of life and is seen more frequently in women than in men [18]. About $25 \%$ of these patients describe parosmia, possibly due to the partial loss of olfactory receptors [21]. In addition to olfactory training, treatment strategies include vitamin A nasal drops or systemic alpha-lipoic acid [22, 23].

Sporadically, acupuncture has been used in postinfectious olfactory loss [24]. Acupuncture is an important part of traditional Chinese medicine Those that use needle acupuncture believe that every living being is filled with the energy "Qi" that flows within the body along meridians on which the individual acupuncture points are located Diseases are explained by disruptions in the flow of Qi $[25,26]$.

The needling of acupuncture points has been shown to be associated with analgesic and relaxing effects It is, therefore, not only positive for the body but similarly for the mental state of the patient Needling stimulates nerves, which results in an activation of the central nervous system [27]. The procedure involves the application of 10-20 needles to certain cutaneous points, where they remain for about $30 \mathrm{~min}$ [28]. The points are determined by palpation The procedure is repeated on different days There should be a noticeable effect, for example in the form of improvement of symptoms, after about 8 sessions on different days [29]. Side effects are rare, with only about $3 \%$ of treated patients describing pain, local infections and hematoma [28].

So far there are only a few studies, that will now be described, that have examined the effect of acupuncture on smell disorders in a controlled way However, previous results already indicate a positive effect of this approach In the study by Vent et al., 15 patients with postinfectious smell loss were treated with acupuncture and compared to 15 patients who had been treated with Vitamin B After 10 weeks of acupuncture treatment, there was a significant improvement in smell function in the acupuncture group compared to the Vitamin B group [30]. However, the significance of this study was questioned later [31]. A non-blinded control condition was used in a study by Dai et al who reported olfactory improvement in postinfectious patients after acupuncture compared to a patient group without treatment [32]. Hauswald et al applied acupuncture in the context of a non-randomized, non-controlled study in a larger group of patients with various aetiologies of smell loss [33]. They reported a significant improvement in olfactory function, especially in postinfectious smell loss Anzinger used laser acupuncture on healthy subjects in a double-blinded singleapplication approach and found a positive, acute effect on olfaction which was measured using the Sniffin' Sticks Test [34]. Furthermore, in a case report smell improvement in one patient receiving acupuncture treatment was reported, this was based, however, on self-assessment [35].

The aim of this single-centre, prospective, placebo-controlled, patient-blinded study was to investigate the change of olfactory function in patients with postinfectious smell loss following 12 acupuncture sessions, twice per week, each 30 min long Based on previous reports, we expected that acupuncture has a positive effect on smell function in postinfectious patients.

\section{Methods}

\section{Patients}

Sixty subjects were recruited consecutively between August 2012 and February 2013 at the Smell and Taste Clinic of the Department of Otorhinolaryngology of the TU Dresden All patients had received the diagnosis of postinfectious smell loss following a detailed, structured history and a full otorhinolaryngological examination including nasal endoscopy [36]. Inclusion and exclusion criteria are listed in Table 1 All participants provided written informed consent The study was approved by the Ethics Committee of the Medical Faculty of the TU Dresden (ethics approval number EK 78,032,012).

\section{Olfactory testing}

The "Sniffin' Sticks" test battery was applied before and after treatment involving tests for odour threshold, odour discrimination and odour identification [37]. The sum of

Table 1 Inclusion and exclusion criteria

\begin{tabular}{ll}
\hline Inclusion criteria & Exclusion criteria \\
\hline Smell loss directly following an URTI & Symptom-free interval \\
18 years of age or older & URTI during the study period \\
Written informed consent & Neurological diseases that may impair the sense of smell (e.g Parkinson's or \\
& Alzheimer's disease) \\
Absence of chronic infection of the nasal cavities or sinuses & Dermatological problems that may complicate the application of the needles
\end{tabular}


the scores from the three subtests resulted in the TDI-score (Threshold, Discrimination and Identification).

\section{Acupuncture treatment}

Subjects were randomly attributed to treatments so that one half received verum acupuncture and the other half received sham acupuncture, sham meaning that fake points, rather than actual acupuncture points were needled Both groups underwent acupuncture 12 times with approximately 2 sessions per week The acupuncture as well as the sham acupuncture consisted of needling specific points using sterile acupuncture needles This was performed by the same person in every session, and in every session the same points were needled.

After completion of the study treatment, patients who had received the placebo condition were offered the verum acupuncture following the conclusion of the study.

The points chosen for the verum acupuncture were comparable to those used in previous studies and can be seen in Image 1 [30, 33]. All points were used symmetrically on both sides of the body.

The points used in the sham acupuncture were the same points used in the ACUSAR- study [38]. The points used are listed in Table 2.

\section{Statistical analysis}

The data were analysed using SPSS 27.0 (SPSS Inc., Chicago, Ill, USA) If not mentioned otherwise, all data are shown as means \pm standard deviation (SD) or numbers (\%), significance level was set at $p<0.05$ (two-tailed test) Pearson statistics were used for correlational analyses.

\section{Results}

Sixty patients, 23 males and 37 females were included in the study The verum group was comprised of 17 hyposmic patients and 13 functionally anosmic patients, the sham acupuncture group of 2 normosmic, 14 hyposmic and 14 anosmic patients All patients completed the study without any exception.

No adverse effects were encountered during the acupuncture sessions Descriptive statistics of the patient groups at baseline are shown in Table 3.

When comparing the change of TDI scores before and after treatment the verum group performed better than the sham acupuncture group $(\mathrm{F}=4.45, p=0.04)$ Concerning individual subtests, only odour discrimination was significantly different between the two groups $(\mathrm{F}=9.48$, $p=0.003)$, but not odour threshold $(\mathrm{F}=2.61, p=0.11)$ and odour identification $(\mathrm{F}=0.93, p=0.34)$ These results can

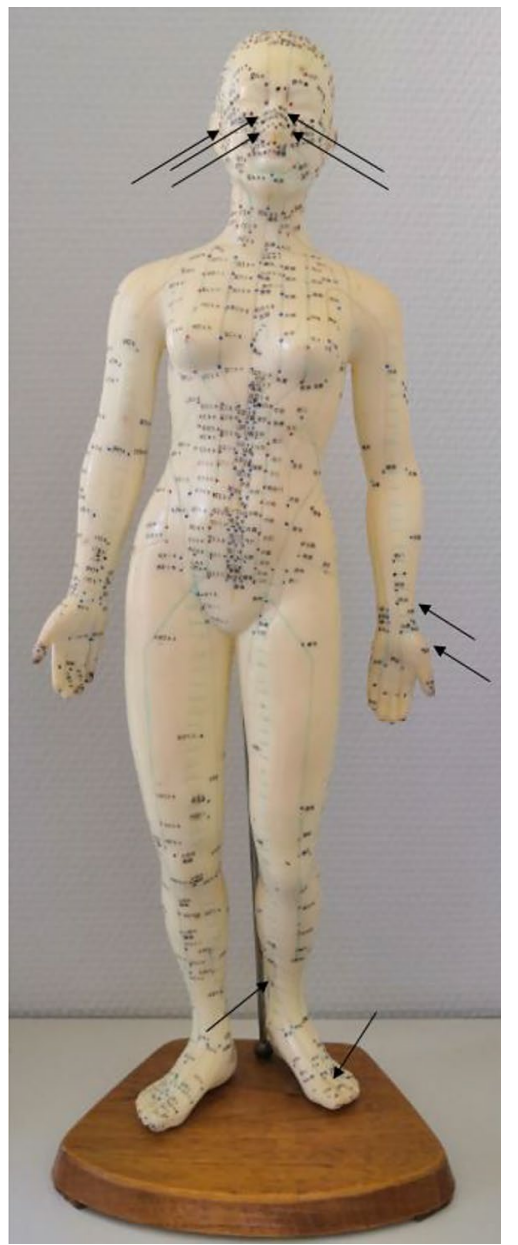

Image 1 Verum-points on face and ear (B1 3, LG23, Di 20, NP 12, Op 16), on the arm (Di 4, Lu 7) and on the leg (MP 6, Ma 44)

Table 2 Verum and placebo acupuncture points

\begin{tabular}{lll}
\hline Location & Acupuncture Points & $\begin{array}{l}\text { Points for } \\
\text { sham acu- } \\
\text { puncture }\end{array}$ \\
\hline Head & Bladder 3 & $/$ \\
& Governing Vessel 23 & $/$ \\
& Large intestine 20 & $/$ \\
Ear & Extra point 12 & $/$ \\
Arm & Ear 16 & $/$ \\
& Lung 7 & Deltoideus \\
Leg & Large intestine 4 & Upper Arm \\
& Spleen 6 & Thigh 1 \\
Back & Stomach 44 & Thigh 2 \\
& $/$ & Back 1 \\
& $/$ & Back 2 \\
\hline
\end{tabular}


be seen in Fig 1 With regard to a clinically significant improvement on an individual level, 6 of 30 subjects from the verum group (20\%) exhibited improvement of more than 5.5 points in the TDI score, whereas only 3 of 30 subjects exhibited improvement in the placebo group (10\%)
[39]. While this is not a statistically significant result, it does deserve mention.

When analysing data across both groups there was a significant correlation between the change of TDI scores and the duration of the disease $(\mathrm{r}=-0.4, p=0.001)$ with
Table 3 descriptive statistics at baseline before treatment; TDI: summated score from odour threshold, discrimination, and identification; standard deviation in brackets

\begin{tabular}{llll}
\hline & Verum acupuncture & Sham acupuncture & $p$-value \\
\hline Age in years & $63.0(13.6)$ & $66.3(10.1)$ & 0.29 \\
duration of smell loss in years & $3.9(4.3)$ & $5.1(5.3)$ & 0.34 \\
TDI score & $17.12(5.62)$ & $17.47(6.99)$ & 0.86 \\
Odour Threshold & $2.08(1.68)$ & $2.29(1.79)$ & 0.84 \\
Odour Discrimination & $8.37(2.53)$ & $8.03(2.99)$ & 0.75 \\
Odour Identification & $6.67(2.83)$ & $7.13(3.57)$ & 0.60 \\
\hline
\end{tabular}

Fig 1 Mean differences (scores after treatment minus scores before acupuncture) of olfactory test results with Standard Errors; * shows significant results
Fig 2 Correlation between changes in TDI scores and duration of smell loss
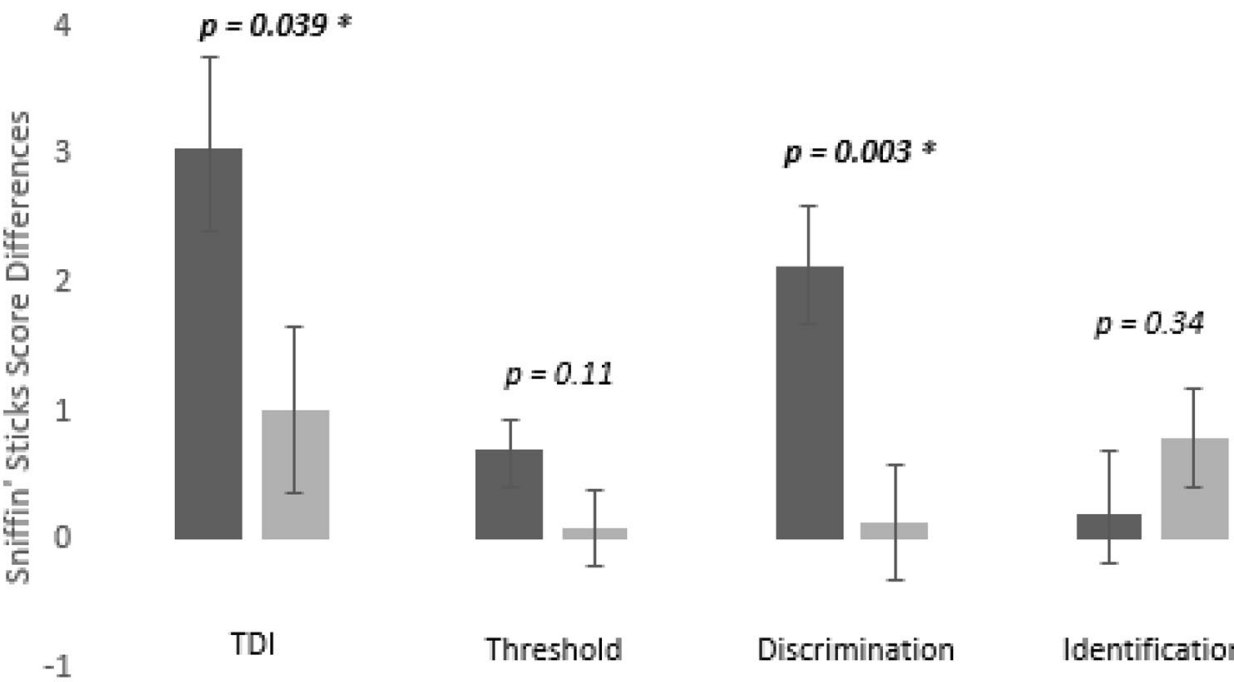

Threshold

Discrimination

Identification
Verum group Placebo group

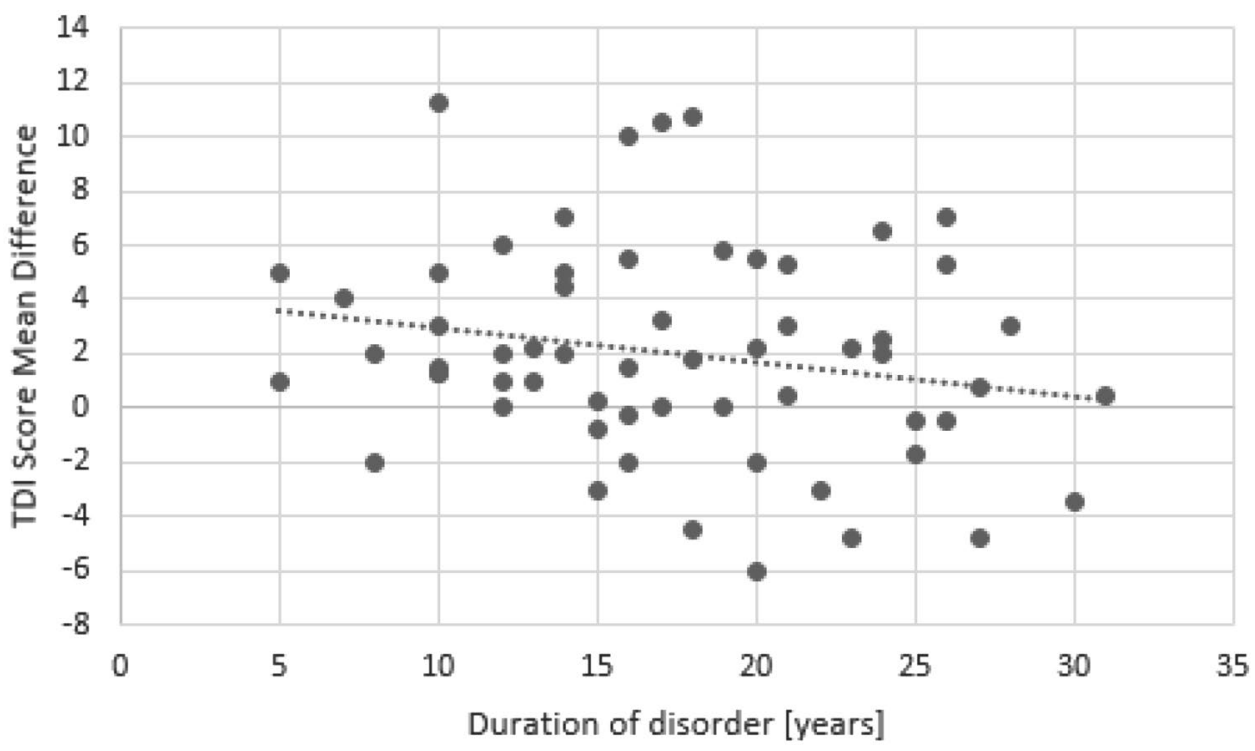


better outcome in patients with a shorter duration of the olfactory loss (Fig 2).

\section{Discussion}

The present results indicated that acupuncture has a positive effect on olfactory function in patients with postinfectious smell loss We found a significant improvement in general olfactory performance as well as an improvement in odour discrimination in verum acupuncture compared to sham treatment On an individual level, verum acupuncture increased olfactory function in $20 \%$ of the subjects compared to $10 \%$ of subjects who had sham acupuncture Further, the treatment response correlated negatively with the duration of smell loss-the longer the smell loss the less likely it was to achieve a positive treatment response A similar relation between the duration of olfactory loss and improvement of olfactory function has been reported several times $[15,40]$. Acupuncture appeared to be useful independently from the patients' age.

The results of our study confirm some of the findings of previous studies. The present research tried to avoid several issues that limited the significance of previous studies, e.g., lack of a control group, heterogeneous patient groups, or low case numbers [30, 32-34]. We, therefore, included a homogenous, thoroughly diagnosed patient group with postinfectious smell loss, and a patient-blinded control condition to minimize possible bias. The therapy was well accepted by the patients, which can be seen from the lack of dropouts and the absence of side effects.

It is interesting to note that odour discrimination, but not odour threshold, improved in response to acupuncture An explanation could be that odour discrimination appears to involve higher-level cognitive functions to a higher degree compared to odour thresholds [41]. Acupuncture has previously been shown to have effects on cognitive function tested with the Mini-Mental State Examination Test in patients following a stroke [42, 43]. Therefore, it might be hypothesized that acupuncture has positive effects on the cognitive processing of odours For example, the outcome of the test might have been positively modified by different levels of attention and concentration.

Acupuncture is an important part of traditional Chinese medicine When analysing this form of treatment, it is important to remember that the classical scientific proof is difficult to obtain when the foundation of the treatment includes something that evades measurement It is, however, possible to focus on the effects of the treatment, which is what was done in this study.

\section{Conclusion}

The present results suggest that acupuncture is helpful in patients with postinfectious olfactory loss. The shorter the time span between smell loss and treatment, the more likely it is for the treatment to have a positive effect.

With hardly any negative side effects being described, acupuncture should be considered as a supplementary treatment.

Future studies need to determine whether the observed increase of olfactory sensitivity is temporary or is lasting for a longer period of time.

Funding Open Access funding enabled and organized by Projekt DEAL.

\section{Declarations}

Conflict of interest The authors declare that they have no conflict of interest.

Ethical approval The study was carried out in accordance with the Code of Ethics of the World Medical Association (1964 Declaration of Helsinki and later amendments) The study was approved by the Ethics Committee at the Medical Faculty of the TU Dresden (Ethics Approval No. EK 78032012) The study design was presented to the volunteers in written form and written informed consent was obtained from each individual participant.

Informed consent Written informed consent was obtained from each individual participant.

Open Access This article is licensed under a Creative Commons Attribution 4.0 International License, which permits use, sharing, adaptation, distribution and reproduction in any medium or format, as long as you give appropriate credit to the original author(s) and the source, provide a link to the Creative Commons licence, and indicate if changes were made. The images or other third party material in this article are included in the article's Creative Commons licence, unless indicated otherwise in a credit line to the material. If material is not included in the article's Creative Commons licence and your intended use is not permitted by statutory regulation or exceeds the permitted use, you will need to obtain permission directly from the copyright holder. To view a copy of this licence, visit http://creativecommons.org/licenses/by/4.0/.

\section{References}

1. Nordin S, Brämerson A (2008) Complaints of olfactory disorders: epidemiology, assessment and clinical implications. Curr Opin Allergy Clin Immunol 8(1):10-15

2. Croy I, Nordin S, Hummel T (2014) Olfactory disorders and quality of life-an updated review. Chem Senses 39(3):185-194

3. Damm M, Temmel A, Welge-Lüssen A et al (2004) Olfactory dysfunctions Epidemiology and therapy in Germany, Austria and Switzerland. HNO 52(2):112-20

4. Bernhardson BM, Tishelman C, Rutqvist LE (2007) Chemosensory changes experienced by patients undergoing cancer 
chemotherapy: a qualitative interview study. J Pain Symptom Manage 34(4):403-412

5. Ogawa T, Rutka J (1999) Olfactory dysfunction in head injured workers. Acta Otolaryngol Suppl 540:50-57

6. Landis BN, Konnerth CG, Hummel T (2004) A study on the frequency of olfactory dysfunction. Laryngoscope 114(10):1764-1769

7. Brämerson A, Johansson L, Ek L, Nordin S, Bende M (2004) Prevalence of olfactory dysfunction: the skövde populationbased study. Laryngoscope 114(4):733-737

8. Fokkens WJ, Lund VJ, Mullol J et al (2012) European Position Paper on Rhinosinusitis and Nasal Polyps 2012. Rhinol Suppl 23:3

9. Fokkens W, Desrosiers M (2019) Harvey R EPOS2020: development strategy and goals for the latest European Position Paper on Rhinosinusitis. Rhinology 57(3):162-168

10. Damm M, Schmitl L, Müller CA, Welge-Lüssen A, Hummel T (2019) Diagnostics and treatment of olfactory dysfunction. HNO 67(4):274-281

11. Hummel T, Rissom K, Reden J, Hähner A, Weidenbecher M, Hüttenbrink KB (2009) Effects of olfactory training in patients with olfactory loss. Laryngoscope 119(3):496-499

12. Haehner A, Tosch C, Wolz M et al (2013) Olfactory training in patients with Parkinson's disease. PLoS One 8(4):e61680

13. Geißler K, Reimann H, Gudziol H, Bitter T, Guntinas-Lichius O (2014) Olfactory training for patients with olfactory loss after upper respiratory tract infections. Eur Arch Otorhinolaryngol 271(6):1557-1562

14. Altundag A, Cayonu M, Kayabasoglu G et al (2015) Modified olfactory training in patients with postinfectious olfactory loss. Laryngoscope 125(8):1763-1766

15. Damm M, Pikart LK, Reimann $H$ et al (2014) Olfactory training is helpful in postinfectious olfactory loss: a randomized, controlled, multicenter study. Laryngoscope 124(4):826-831

16. Hummel T, Whitcroft KL, Andrews P et al (2017) Position paper on olfactory dysfunction. Rhinology, Suppl 25(2017):1-30

17. Daramola OO, Becker SS (2015) An algorithmic approach to the evaluation and treatment of olfactory disorders. Curr Opin Otolaryngol Head Neck Surg 23(1):8-14

18. Hummel T, Hüttenbrink KB (2005) Olfactory dysfunction due to nasal sinus disease Causes, consequences, epidemiology, and therapy. HNO 53(Suppl 1):S26-32

19. Brann DH, Tsukahara T, Weinreb C et al (2020) Non-neuronal expression of SARS-CoV-2 entry genes in the olfactory system suggests mechanisms underlying COVID-19-associated anosmia. Sci Adv. https://doi.org/10.1126/sciadv.abc5801

20. Tian J, Pinto JM, Cui X et al (2016) Sendai Virus Induces Persistent Olfactory Dysfunction in a Murine Model of PVOD via Effects on Apoptosis, Cell Proliferation, and Response to ants. PLoS One 11(7):e0159033

21. Hong SC, Holbrook EH, Leopold DA, Hummel T (2012) Distorted olfactory perception: a systematic review. Acta Otolaryngol 132(Suppl 1):S27-31

22. Hummel T, Whitcroft KL, Rueter G, Haehner A (2017) Intranasal vitamin $\mathrm{A}$ is beneficial in post-infectious olfactory loss. Eur Arch Otorhinolaryngol 274(7):2819-2825

23. Hummel T, Heilmann S, Hüttenbrink KB (2002) Lipoic acid in the treatment of smell dysfunction following viral infection of the upper respiratory tract. Laryngoscope 112(11):2076-2080

24. Tanaka O, Mukaino Y (1999) The effect of auricular acupuncture on olfactory acuity. Am J Chin Med 27:19-24

25. Hesse HP (2007) Akupunktur. In: Likar R, Wendtner F, Wenzel G, Ausserwinkler M, Sittl R (eds) Bernatzky G. Nichtmedikamentöse Schmerztherapie - Komplementäre Nethoden in der Praxis. Springer Verlag, Wien, p S 385-390
26. Stux G, Stiller N, Pothmann R, Jayasuriya A (1985) Akupunktur-Lehrbuch und Atlas 2 Auflage. Springer Verlag, BerlinHeidelberg, p S 10-16-S 29-33

27. Stux G (2007) Akupunktur-Einführung, 7th edn. Springer-Verlag, Berlin, p S.9-36-S.57-186

28. Stux G, Stiller N, Berman B, Pomeranz B (2008) Akupunktur Lehrbuch und Atlas, 7th edn. Springer Verlag, Berlin

29. Stör W, Irnich D (2009) Acupuncture: basics, practice, and evidence. Schmerz 23(4):405-418

30. Vent J, Wang DW, Damm M (2010) Effects of traditional Chinese acupuncture in post-viral olfactory dysfunction. Otolaryngol Head Neck Surg 142(4):505-509

31. Silas J, Doty RL (2010) No evidence for specific benefit of acupuncture over vitamin B complex in treating persons with olfactory dysfunction. Otolaryngol Head Neck Surg 143(4):603

32. Dai Q, Pang Z, Yu H (2016) Recovery of Olfactory Function in Postviral Olfactory Dysfunction Patients after Acupuncture Treatment. Evid Based Complement Alternat Med. https://doi.org/10. $1155 / 2016 / 4986034$

33. Hauswald B, Tänzer K, Hüttenbrink KB (1998) Die Ergebnisse der Akupunktur bei Patienten mit Hyp-bzw Anosmien. In: Hauswald B, Tänzer K, Hüttenbrink KB (eds) Allergische Erkrankungen von Haut und Schleimhäuten-Akupunktur im Dialog. Hippokrates-Verlag, Stuttgart, p S 67-71

34. Anzinger A, Alberecht J, Kopietz R et al (2009) Effects of laserneedle acupuncture on olfactory sensitivity of healthy human subjects: a placebo-controlled, double-blinded, randomized trial. Rhinology 47:153-159

35. Lin PS, Luo SD, Huang OY (2019) The application of bo's abdominal acupuncture on post-viral olfactory disorder after steroid treatment failure: a case study. J Chin Med 30(2):119-129

36. Welge-Luessen A, Leopold DA, Miwa T (2013) Smell and Taste Disorders - Diagnostic and Clinical Work-Up. In: Welge-Luessen A, Hummel T (eds) Management of Smell and Taste Disorders - A Practical Guide for Clinicians. Thieme, Stuttgart, pp 49-57

37. Hummel T, Sekinger B, Wolf SR, Pauli E, Kobal G (1997) "Sniffin" sticks': olfactory performance assessed by the combined testing of odor identification, odor discrimination and olfactory threshold. Chem Senses 22:39-52

38. Brinkhaus B, Witt CM, Ortiz M et al (2010) Acupuncture in seasonal allergic rhinitis (ACUSAR)-design and protocol of a randomised controlled multi-centre trial. Forsch Komplementmed 17(2):95-102

39. Gudziol V, Lötsch J, Hähner A, Zahnert T, Hummel T (2006) Clinical significance of results from olfactory testing. Laryngoscope 116(10):1858-1863

40. Reden J, Mueller A, Mueller C, Konstantinidis I, Frasnelli J, Landis BN, Hummel T (2006) Recovery of olfactory function following closed head injury or infections of the upper respiratory tract. Arch Otolaryngol Head Neck Surg 132(3):265-269

41. Hedner M, Larsson M, Arnold N et al (2010) Cognitive factors in odour detection, odour discrimination, and odour identification tasks. J Clin Exp Neuropsychol 32(10):1062-1067

42. Liu F, Li ZM, Jiang YJ, Chen LD (2014) A meta-analysis of acupuncture use in the treatment of cognitive impairment after stroke. J Altern Complement Med 20(7):535-44

43. Zhou L, Zhang YL, Cao HJ, Hu H (2013) Treating vascular mild cognitive impairment by acupuncture: a systematic review of randomized trials. Zhongguo Zhong Xi Yi Jie He Za Zhi 33(12):1626-30

Publisher's Note Springer Nature remains neutral with regard to jurisdictional claims in published maps and institutional affiliations. 